\title{
Vecchio Siculo
}

\section{Vecchio Siculo,}

hai attraversato la vita senza un bacio di felicità.

E finalmente sei giunto alla tua cadente età con un volto che mostra 1 miel millenni stanchi coronati di sofferenza, di desideri assopiti e di speranze che ancora osano guardare un futuro che non promette luce.

Ti riconosco Frate110

perché sei come me, e negli occhi

hai ancora quella luce

e quella forza che ci fa partecipi dello stesso eterno destino...

Ti guardo, e vedo lacrime invisibili scorrere sulle tue guancie solcate dalla fatica di vivere -- In silenzio gridi la tua esistenza disperata: Ma non essere triste Vecchio Uomo delle Montagne, il sole anche dovrà un glorno spegnersi, e tu allora dall'Isola t'alzerai, Nuovo Icaro, in volo verso $l^{\prime}$ infinito... 